\title{
BARRIERS OF MARKETING EFFECTIVENESS AND EFFICIENCY WITHIN COMPANIES: A QUALITATIVE STUDY
}

\author{
Miroslav Karlíček, Zuzana Chytková, Ladislav Tyll, \\ Hana Mohelská
}

\section{Introduction}

The marketing function is based primarily on fundamental strategic decisions like "Who is our ideal customer", "What is the value we propose", "How we ensure customers' satisfaction", "How we retain the competitive position" etc. [4]. Answering these questions correctly ensures that the company will stay market-oriented and thus will be able to adapt to the ever changing market conditions.

Market orientation can be defined as the company's ability to systematically generate relevant information about current and latent customer needs, spread this information across all company departments and use this information in decision making and subsequent behavior [3], [7]. Market orientation can be hence viewed as the degree to which the company includes information about the external environment into its strategic planning [1]. Last but not least, market orientation can be defined as the culture that places the highest priority on the profitable creation and maintenance of superior customer value and that provides norms of behavior regarding the organizational development of and responsiveness to market information [16].

Current research proves that market orientation correlates strongly with profitability (e.g. [10]). Strengthening market orientation of the company should therefore be the main focus of the marketing department. The Chief Marketing Officer (CMO) or his/her alternate should be, at the same time, the main coordinator of the marketing function.

However, over the last years, marketers within companies have faced serious criticism coming from the top management as well as from other business functions (such as finance, sales or production). Such criticism stems from the generally shared opinion that marketing expenditures tend to rise whereas marketing effectiveness and efficiency seem to decline over time, as proved by relatively low satisfaction and loyalty levels of customers and their resistance towards marketing activities [14]. By "effectiveness" we understand ability to achieve marketing goals, whereas by "efficiency" we understand the extent to which marketing costs are well used by achieving those goals.

\section{Literature Review}

In literature, various reasons for low effectiveness and efficiency of the marketing function can be found. They include insufficient control of CMOs over marketing strategy and marketing mix, lack of convenient measures for capturing effectiveness and efficiency of marketing investments, tactical and short-termed orientation of marketing departments, and last but not least low reputation of the marketing profession [6].

Insufficient control of CMOs over marketing strategy, and particularly over activities that influence customer acquisition and retention, lowers deeply the company's ability to create marketing assets such as brand value [14]. That such low control of CMOs over marketing mix exists even in multinational, seemingly market-oriented companies, was demonstrated for example by a recent survey of IBM [2], in which 1,700 marketers were interviewed covering 19 sectors and 64 countries. According to the research, the marketing department had a relatively strong influence over communicationrelated marketing activities such as advertising, 
external communications or social media. On the other hand, their influence over other components of the marketing mix (i.e. price, product and distribution) was limited. Only less than half of the respondents stated they had control over issues such as pricing, new product development or distribution strategy.

The effectiveness of the marketing function is not only affected by the level of the marketing department's control over marketing strategy. Clearly, even the best marketing strategy will not have the pursued effect, if not comprised in the company's strategic plans. The strategic influence of CMOs, however, seems to be limited too, as illustrated by a recent survey among 227 Czech marketing directors. The results showed that only $14 \%$ of the respondents considered marketing department as the most influential in constituting the overall company's strategy [4], while the most decision power appears to be afforded to the sales department (it was mentioned as the most powerful department by $55 \%$ of the respondents), followed by the financial department (mentioned by $22.5 \%$ of the respondents). However, differences were found over sectors. The influence of marketing department was conclusively the highest in the FMCG sector, since almost $40 \%$ of the CMOs working in this area stated that their department played the most powerful role in their company. Other sectors were far behind.

Another serious problem of marketing's effectiveness and efficiency is the inability of marketers to evaluate their activity appropriately. Marketing ROI is perceived as one of the biggest and most important challenges by marketers themselves, as shown for example by a study among US marketing directors, $83 \%$ of whom stated that demonstrating return on marketing spending is their top priority. Moreover, more than half of them consider current metrics for measuring marketing ROI insufficient [17]. Similarly, in the study of IBM [2] introduced above, only $44 \%$ of the respondents believed that they were sufficiently prepared to provide "hard numbers" that would relate marketing spending to financial results of the company.

The felt inability to link the marketing spending to financial results, however, may not be due to the inexistence of adequate metrics. Many companies still measure marketing effectiveness on the basis of profit, sales or market share. Unfortunately, from marketing point of view this is not the most suitable approach, because relationship of these indicators to marketing effectiveness is usually not direct and because a number of key marketing activities do not have an immediate effect on the overall results of the company [21]. Moreover, these indicators support short-termed orientation of companies, whereas building customer relationships and brands requires longer perspective. However, although relatively new measures exist that allow for quantifying the long-term effect of marketing spending (e.g. Customer Lifetime Value), they are still used only exceptionally [11]. The key reason for inappropriate (or the lack of) usage of available metrics may be the lack of analytical, financial and IT skills of marketing managers [21], [22]. Consequently, under these circumstances, marketing expenditures are perceived as "soft money" which can easily be cut, rather than as investments [13], [12].

The generally adopted approach to quantifying marketing expenditure and company's financial standing prioritizes short-term orientation. Short-term orientation of marketing departments is further strengthened by high fluctuation rate of marketing managers. Managers responsible for marketing strategies and their implementation change positions at very short intervals (often shorter than two years). This means that before marketing strategy is implemented and evaluated, responsible manager leaves [9]. The vision of rapid promotion governed by positive short-term results naturally stimulates short-term behavior of marketing managers, who then lean towards sales mentality [22], ignoring long-term impact on customers. Marketing managers can thus support programs which generate immediate profits (e.g. discount promotions, unfair and annoying marketing practices, risky brand extensions etc.), but which at the same time reduce the level of customer satisfaction and loyalty. This strategy, however, is not market oriented and does not bring longterm effects. In fact, according to a recent Teradata study [20] among 1,100 marketers from 19 European countries, short-term orientation of marketing departments was considered the biggest barrier of marketing effectiveness.

All of the barriers mentioned may have negative effect on the credibility of marketers in the eyes of their colleagues and top management. As shown in a study that measured how are US marketers perceived by their 
colleagues from other business functions, only $38 \%$ of the respondents evaluated their marketing colleagues as good or excellent, only $18 \%$ perceived them as result oriented and only $34 \%$ believed that marketers in their company were strategic thinkers [15]. Low credibility of the marketing profession can be guessed also from the compensation of marketers in relation to other business professions. In the US, average salary of a marketing manager represents $69 \%$ of finance manager's salary and $91 \%$ of production manager's salary [19]. It also seems that being a marketing manager is not the best precondition for the CEO position. Among the hundred most important British companies, for instance, there are twice as many CEOs with financial background than with marketing background [19].

The above described barriers of marketing effectiveness and efficiency correspond well with determinants of market orientation as described by Jaworski and Kohli [3]. These researchers proved that market orientation correlates with short-term versus long-term orientation of the company's compensation system (long-term orientation correlates with market orientation positively), relationships among individual company's departments (both formal and informal interconnection among departments correlates with market orientation positively) and last but not least the approach of top management towards market orientation (continuous support of top management towards market orientation and low aversion towards risk correlate with market orientation positively). As market orientation has proved to be one of the key determinants of profitability [10], it seems to be most desirable to overcome the barriers of marketing effectiveness and efficiency. However, the general barriers described above can manifest locally in heterogeneous ways depending on the local context. Also, the barriers described in (mostly international) literature may or may not correspond to barriers perceived by local marketers. To give specific recommendations in a specific context, it is thus necessary to complement our understanding of the issue.

\section{Goal of the Study and Methodology}

The goal of this study is identification of the main barriers of marketing effectiveness and efficiency which are perceived by Czech marketing managers. These findings should be of high importance for both CEOs (resp. owners) and marketers, because increasing effectiveness and efficiency of the marketing function is their common goal. However, we also want to extend the current literature, as it is highly fragmented and US focused and individuate barriers that may be context-specific.

Our study is based on two focus groups realized in cooperation with the research agency Millward Brown. The first focus group was realized with 5 marketing managers, the second with 7 marketing managers. All of the respondents were senior marketing managers. They worked in marketing departments of various sizes (in 4 cases they worked in large marketing departments of tens of employees, in 3 cases they worked in departments of less than 10 people, and in 5 cases they were the only marketing professional in the company) and various levels of internationalization (in 3 cases they worked for local companies, and in 9 cases for subsidiaries of multinational corporations). Respondents worked for companies operating in different sectors: 4 in FMCG, 5 in B2B, 1 in services, 1 in retail and 1 in durables. However, during their career, most of them gained experience from more than one sector. Each of the respondents was motivated to participate by a small incentive (1,000 CZK).

Each of the sessions lasted approximately 90 minutes. The moderator focused on three main fields. He asked first how respondents perceived themselves as marketers, second how they believed their colleagues and superiors perceived them, and third what were the main barriers for effectiveness and efficiency of their activities. For the first and the second questions field projective techniques were used, as they are facilitate the expression of deep and difficultly communicable thoughts through metaphors.

Both focus groups were recorded on DVD and subsequently transcribed verbatim. In order to translate the respondents' emic experiences into etic categories, the data was then analyzed through the operations of categorization, abstraction, comparison and iteration [18].

\section{Findings}

The focus groups revealed several key themes that reflect how local marketers perceive their jobs. Their account exemplifies the locally lived experience of the barriers to marketing's 
effectiveness and efficiency as described in literature, but also identifies other barriers not mentioned in other studies.

In the following, we will first illustrate what marketers see as the main content of their jobs including the perceived strategic/operational nature of their work and their perceived influence over the company's overall strategy and marketing mix. We will then turn to marketers' image in the rest of the company and finally to the instruments used for measuring marketing's effectiveness and efficiency within the company. In this way, it will be possible to assess the existence and importance of these barriers at the local level. The last part of findings will then engage with the barriers specific to the local context.

\subsection{Marketing: A Job with Vastly Different Content}

Based on the respondents' accounts, it is clear that marketing differs greatly over various types of companies and over various sectors. Thus, while some respondents described their job as very comprehensive starting from marketing research, over strategic marketing (brand management, CRM, product innovation etc.), to more or less operational marketing (product portfolio management, pricing, marketing communications etc.), others gave a picture of their work as founded practically only in marketing communications (e.g. events and trade shows organization, media relations, advertising, website management, brochures and newsletter creation etc.). In the second case, marketing was understood as a supporting function for the sales department and its main goal was attracting new customers (see e.g. [8]). As most respondents experienced marketing practice in different types of companies and different sectors, they can also give a more comprehensive account of its different manifestations.

I've experienced various scenarios in which marketing executed communications only, or the other side of the spectrum, in which marketing department developed new products, managed pricing, price lists, margins, dealt with ordering of goods - it was quite wide. (retail)

I worked in FMCG for 10 years and there marketing is really ATL, BTL, research and that's it. [...] Here [financial sector] it's different, because we are expected to manage the company in terms of product innovation, call center, digital media and we sell online as well. (financial)

The content of the marketing function seems to depend partly on the customers it serves (B2B, B2C), the sector it operates in (FMCG, banking, retail, special goods etc.), but also on the type and size of company (multinational corporations, locally owned companies). Marketing in B2B companies appears to be more sales-supportive or even sales-identical than on B2C markets. What seems to have a major influence for the orientation of the marketing department, however, is the size and geography of the ownership. Marketing seems to be attributed less importance in locally owned and smaller companies.

Although our turnover is quite good for being a Czech firm, I'm the only person that does marketing for the whole world. [...] I mostly move in the dark waters, where I try to work with a small budget. (durables)

Furthermore, due to the perceived high cost of market data, marketers at smaller companies in particular tend to suffer the lack of market information. Often, they do not undertake any marketing research and therefore have no idea about customer preferences, brand awareness etc.

When I only mention "research" of anything, everybody grabs rash and it is finished [...] I wish I could realize some research. (durables)

Larger companies have enough market data at their disposition. However, marketers from larger companies spend a lot of energy on administration (emailing, writing statuses and reports, long day meetings etc.), on processing of the enormous amount of data and on negotiation with other departments or the headquarters.

Understanding the consumer should be the main content of the [marketer's] job, although it sometimes gets wild [...] statuses, e-mails and also the different tables [...] all day long meetings, always saying something and solve "Are you going?", "You will not go?", "Well, I have to be there, at least just sitting". And 
I think it is a big waste of time. These are the sort of strange bonds, you do not have to be there, but everybody expects it. (FMCG)

I feel like I keep targeting someone [consumers, headquarters, colleagues], I keep picking the right information from the huge database that exists for each product (FMCG)

The time of recession seems to further alter the content of marketing, in most cases to the worse. Several respondents mentioned cuts in marketing spending and the subsequent further narrowing of the marketing's field of influence, as one of the main solutions companies adopt when facing recession.

Since 2008 when the recession started [...] there were three areas that were hit by huge cuts: investment, human resources and marketing. [...] So the role of marketing right now is this broken person. [...] Now we don't make analyses, we don't collaborate with research agencies, because of course it is not for free and the cost is significant and obviously strategic decisions suffer by that, too, and we don't exactly have many new products (FMCG).

The content of the marketing job conditions the degree of control over the overall strategy. Clearly, in cases where the marketing function is rather independent and given enough responsibility, it also defines questions regarding the whole marketing mix. Such department then engages in product innovation and development, defines pricing strategy, etc. which allows to pursue market orientation.

We are responsible for all activities of the company, we are supposed to drive things, we are pressed to have the thumb over most of the important steps [...] marketing creates the strategies. (FMCG)

Where marketing is limited to a very narrowly defined communication, the strategic decisions are also beyond their sphere of influence.

We deal primarily with communications, above the line, bellow the line. We do not talk into product range, prices. (retail)
With us marketing is from research, through promotional items, inventing competitions, to posters development. (B2B)

The content of the marketing function, its effectiveness and efficiency, and the connected issue of marketing's influence over the overall strategy of the company (i.e. the level of overall market orientation) depends also on the person of CEO (or owner) and his/her professional background. CEOs with marketing background tend to understand the importance of long-term market orientation and the role of marketing. Thus, they delegate wider competencies to marketers, support their efforts and allow for a bigger influence of marketing in the overall strategy.

My best experience was in a company with CEO who was a marketer. He gave marketing great competences - marketing was managing pricing, margin, defined product range, innovations on the market etc. However, this was connected with responsibility - what will be the revenue and profit in each category - it was up to us how we will coordinate our colleagues in sales and other departments. It worked very well. But not everyone is so enlightened. (retail)

On the other hand, CEOs with sales, production or financial background may be a significant barrier for an efficient marketing function.

If there is no support from the owner, or the $\mathrm{CEO}$ and top management, it becomes a problem. (FMCG)

Our CEO is a former marketer and you can tell. Our former CEO was from sales and it is clear that this one is more helpful. (FMCG)

Our top management comes from production, thus production is the priority, and then sales support. (FMCG)

We have a director who used to be sales director [...] Marketing is a support, which does not have any say in planning. (B2B)

In cases where the top management is not inclined to include marketing in more strategic 
decisions, marketers have to, according to respondents, work hard on building trust with the top management and negotiate.

The negotiation with top management has its particularities depending on the type of the company: local or multinational. While in the locally owned businesses, there is often a lack of understanding of marketing itself and thus a certain mistrust towards operations that tend to be costly, multinational companies often do recognize the importance of marketing, but are managed centrally. Local subsidiaries are then often controlled by the multinational headquarters, where strategic marketing decisions are taken and communication campaigns prepared. Local marketing department is then responsible only for localization of those campaigns and reporting, and have a very small space in which to effectuate efficient marketing, as described in literature [5]. In their case, continuous negotiation with the headquarters makes up a significant part of their job.

It's a lot of negotiation with the headquarters, what they authorize and what not. (FMCG)

We were reporting all day long, we did not do anything else. (FMCG)

Marketers from subsidiaries with strict control seem to perceive the role of headquarters negatively. They believe that authoritarian control from the headquarters caused ineffectiveness and need of evasive maneuvers.

Sometimes the orders from headquarters were directly against the interests of our local business. (B2B)

Certainly it would help us if they gave us more space, more trust and opportunity to fulfill our strategies, which we defined here and if they gave a little more money. (retail)

We try to go in the direction declared [by the headquarters], but sometimes we look for our own unexplored terrain and do things a little bit differently or even guerrilla-like, I admit. These are fortunately fields that are almost completely under our control, such as PR or Facebook. (retail)
On the other hand, some marketers from subsidiaries stated that headquarters give them adequate freedom. These marketers seemed not to perceive the role of headquarters negatively.

They do not want us to do as many numbers and analysis [...] and as we have many specifics in comparison to the mother company, it's nice to do marketing here. Although we have many things give [by the headquarters], but it is only a recommendation and it's not what we have and do or have to prove afterwards. (B2B)

\subsection{Magicians or Trouble-Makers? Marketers' Image within the Company}

The content of the marketing function, its strategic influence and the understanding of top management are not the only issues that preclude marketing's effectiveness and efficiency. Another barrier is represented by the marketers' image and support within the company. This issue described in literature was documented by our respondents who felt that their colleagues do not comprehend what is the essence and contribution of marketers' job and perceived this lack of comprehension as a significant barrier for their job. Moreover, according to our respondents, they were often perceived as a department that only consumes financial resources earned by other departments.

I feel that our people still do not know what to imagine under "marketing". When you say "doctor" or "dentist", you automatically associate it with something. I believe that if I asked what I was doing they would name some partial things, but they would definitely not describe the fundaments. (B2B)

Everybody makes money in the other departments, but it's just me in marketing to spend it [...] Marketing is thus generally perceived as a department which gives out money, and it is basically true, because I consume money visibly. (FMCG)

The image of marketers within companies seemed to be often stereotypical and often based on images originated in popular culture. Respondents believed that they were often perceived as people who focused primarily on 
"image" or entertainment, not on substance. Also, they are seen as those who understand things only superficially and who are slightly out of reality.

We were perceived as girls who have fun all the time, inventing nonsense, spending money that others earn, who make it difficult to work when having an all day meeting, because it's just laughter, guffaws and screaming... (FMCG)

A lot of my friends think that I'm living like the Mel Gibson movie "What Women Want." (financial)

They perceive us as people with ties who sometimes take this or that to pieces, do not understand things properly, but have gelled hair. (financial)

The misunderstanding of marketers' job also causes other colleagues to blame the marketing department when something goes wrong, even though the marketing does not possess appropriate competences. Respondents even mentioned that other departments tended to be averse towards activities they proposed.

If things go wrong, it is because of marketing, but it's never because they [the sales] would not succeed. (B2B)

When something goes wrong, it is marketing's fault. (retail)

Despite of these misperceptions, respondents agreed that their success was strongly dependent on others and that cooperation with their colleagues from other company's departments was one of the cornerstones of their job. Thus, the lack of understanding creates a serious barrier for effective work also because it is one of the reasons for a constant negotiation with other departments, which represents a source of demotivation and low effectiveness.

I have to target [persuade] somebody all the time... the sales reps to sell my product well and ensure its good exposure... I have to defend my stuff in front the parent headquarters. (FMCG)

After some time, you lose motivation to constantly argue with someone. There are things you found out you cannot change and it is quite annoying to come back the next year and see that you still cannot move them [...] Emotionally you feel that a lot of things should be different, but you do not devote your energy to support them [the changes] with arguments.. (financial)

A solution to this problem may reside in "internal marketing". As confirmed by the respondents, although it represents a potential source of frustration, strong "internal marketing" offers a way to ensure that marketing is perceived as an investment rather than a mere expenditure and should thus be of highest priority. Consequently, respondents working in companies that allow for such endeavor, try to engage their colleagues from other departments in informational sessions and/or marketing operations to educate them about marketing department's processes and their motivations.

Each quarterly period, when new products were launched, we invited accountants and all other colleagues not involved in marketing to participate in a session where we seemingly wanted to present the new products and distribute samples. Within this session each of us was to somehow present how much the company earned by our decisions or marketing activities [...] It took about one year [...] before people stopped going there just for the samples.. (FMCG)

Interestingly, the current recession that on the one hand caused cuts in spending and further movement towards short-term orientation, also opened up opportunities especially in internal marketing. This is documented by the respondents' accounts of how the low sales justified the involvement of other departments in marketing operations or how marketing serves as a tool to liven up other employees in times of bad news.

We went to all the people [in the company] and told them: "When you go to the drugstore or a supermarket to shop, look what's wrong with our brand, look for missing products or competition in our stands. This work will not cost you much time and it is extremely important to us". This worked pretty well. (FMCG) 
Our colleagues $[\ldots]$ often hear how terribly bad the whole sector of construction is doing, so that's why sometimes it's good to show them our numbers. [...] To show them what they hear everyday in the media in a little brighter colors. (B2B)

However, since it requires a lot of effort, respondents also found internal marketing as exhausting and thus often not sustainable in the long term.

I think that we are not very good in the internal work [...] or that we have lost appetite to do it [...] We can say that the boss is just thickheaded because he does not get this. But it is more my fault, because I cannot somehow sell it to him. It's about marketing and we ourselves are not able to do it. It is easy to put something on TV, because I like it, but to sell an idea inside [of a company] is really difficult. (financial)

The difficulties that marketers encounter within the company and the efforts they have to exert to overcome them (not always successfully) are some of the main reasons for high fluctuation rate of marketing managers that, according to our respondents, further undermines effectiveness and efficiency of marketing, because each new marketing director tends to bring a radically new brand strategy. Long-term marketing strategy is thus impossible.

As with the content of marketing, however, even in the field of cooperation with other departments there are differences among companies, especially across their different sizes.

Unsurprisingly, small companies with an owner or just a few employees seem not to have very serious problems with communication and coordination of the marketing function. In this case it is the owner (or CEO) who has the final decision power regarding all marketing questions. The communication among the business functions is also relatively simple.

Because we have just two salespeople and one marketer for the whole world, we always find an agreement. (durables)

We have a marketing department with two people, sales department with just a few people and one technician only, so in comparison to large departments the communication runs simpler. (B2B)
Smaller companies, as I know them, do not have divisions, there is the owner who is in charge of absolutely everything, managing sales, price or marketing creative strategies. This is what is strictly divided in large firms. (B2B)

Larger companies, on the other hand, seem to have significant problems with coordination of the marketing function and the consistency of marketing decisions.

\subsection{Problems with Proving Return on Marketing Investments}

Another serious barrier to marketing's effectiveness and efficiency individuated in the literature is the inability to prove return of marketing activities. This problem was confirmed by our respondents who perceived it as one of the reasons behind low credibility of marketers within companies. They highlighted, however, that many activities in marketing were difficult to measure (for example because the effects of marketing tools often overlap) and many marketing activities therefore stay unmeasured. Marketers are then left with intuition and trial/error method or common sense. In this regard they proposed that some level of intuition is necessary in marketing, as well as some rate of failure.

We have a few projects on which it is easy to see what marketing brings, but it is really just a few. (B2B)

If I could measure everything [...] it would help us enormously [...] but it is not always possible [...] I personally, even though I know that it is necessary to measure, evaluate and so on, I fight this in practice and try to do some things more intuitively. And then it turns out to be trial and error method, I admit. (B2B)

[To measure the effect of mass-media campaign] it is more trial/error method. We use a campaign, then try something else and compare the sales." (retail)

One cannot rely only on the data and without data it is not possible. Ideally, both should be linked. (FMCG)

However, over the last years, the measurement capabilities in marketing had improved 
significantly. The respondents saw this especially as a contribution of digital marketing and loyalty programs which bring an overwhelming amount of customer data. Especially activities in the online environment can be easily evaluated, which motivates marketers to use digital marketing tools (e.g. SMS campaigns) rather than less measurable tools (e.g. radio or print advertisement). Respondents believed that moving from mass media to more targeted oneto-one media was an important trend. They found this transition easy to defend in front of both CEO and CFO, because it brings better measurability and higher efficiency.

Fortunately, the number of instruments that allow to measure and evaluate is growing. We control the whole sales process, we have our shops, our cashier system, information system, loyalty program and it is all very well connected. We think of a promotion, something like $20 \%$ off, there are coupons for this, so online we can see immediately what impact does it have. (retail)

However, an exaggerated switching to measurable processes in general and digital marketing in particular has its pitfalls, as documented by a respondent who noted that this transition might be sometimes artificial, responding to the need of measurability whereas actual effectiveness may be neglected.

To activities, that we are able to evaluate, we attribute greater credibility than those that are evaluated with a bit more difficulty. I think the sobering up in the world was relatively quick. In Britain, all rushed to the internet. "Well, we measure clicks, conversions, we have a webpage, we have fans on facebook." And they fell back from the traditional media and all of a sudden their brand started to erode and they found out that even though they optimized the banner no matter how [...] nobody clicked on it, because they did not have any reason. The brand was not sexy. (B2B)

Within the field of traditional measures, the most important criterion for evaluating the effectiveness of marketers' work tends to be profitability, turnover, or market share. Respondents were aware that these criteria lead them to short-term orientation. However, they did not see many possibilities for a change as shortterm pressures tend to be caused by top management.

They [the management] have a really short-term perspective... We do not talk about brand perception, where we want to aim... It is difficult. Unfortunately, short-term goals prevail. (retail)

The top management pressure was strengthened by the current economic recession that, as with the general role of marketing, also altered the way measures are used. Because there has been a growing pressure to cut spending, clearly what is sought is the justification for costs. As a result, pressures from the top management towards marketing accountability had been rising. Any improvement in justifying effects of marketing expenditures and investments is thus believed to be really helpful, especially in case the CEO was not very marketing literate. Respondents therefore agreed that they tried to measure effectiveness of as many activities as possible.

The pressure from up to do measurable things is growing. Because when there are cuts, the question is where and if you have arguments that you cannot cut this or that because it works and you have numbers, it is a strong argument. [...] pressure on the measurability of everything possible is certainly a step in the right direction. (retail)

However, there seems to be the effect both of the market the company operates on (B2C/B2B) and of the company's ownership (privately owned/stock company). In case of $\mathrm{B} 2 \mathrm{~B}$ companies, there is more pressure on retaining customers. Marketers from B2B companies thus use longer-term criteria for evaluating effectiveness of their marketing activities, especially customer satisfaction and customer loyalty.

Privately owned companies, as opposed to stock companies, tend to have other primary goals than short-term profit. Also, if the company has a private ownership, the business culture of the ownership becomes more crucial (e.g. Japanese culture). When it is a stock company, there is more pressure on short-term profit. This is more often true for big 
multinational corporations operating in FMCG sector.

We measure the loyalty of the customers [...] and how many new customers we have, that is all for us. (B2B)

For us it's definitely loyalty. It is watched a lot and each lost customer is talked about and analyzed and it's a big problem, we just did something wrong." (B2B, privately owned)

[...] the CEO is evaluated based on the results. It is complicated. I understand that if a Japanese company has been around for 400 years, they have a certain idea, but if you have shareholders it's another story. Somebody from Germany comes and says: "I'm here just to collect money for my shareholders. I'm not interested in anything else" (financial)

Long-term measurements offered by marketing literature such as Customer Lifetime Value or profitability of individual customers do not seem to be in use and were not even mentioned. Longer term marketing visions stay therefore very often just on paper.

The short-term and more tactical orientation of some companies may thus be caused by the perceived lack (factual lack of knowledge of) and inaccuracy of long-term measuring methods.

[to measure sales] is possible only for the tactical campaigns that you do on weekly basis. Then there are marketing goals that are very far away and you have to head there for a long time, because otherwise the brand will not live." (B2B)

\subsection{Locally Manifested Barriers}

Except for the barriers described in literature, our respondents individuated other issues that prevent the marketing function in their companies from being effective and efficient. First of all, what was found in locally owned companies was the unwillingness to alter the known processes, to alter the "way things are done". As one of the respondents notes:

It is a closed group of people [in the business sector] who are not even interested in letting other ideas and other people in and altering their way of thinking. (FMCG)
In this case, even the internal marketing activities may not be sufficient to alter the top management's view of marketing. Marketing is thus limited to the top management's perception of what it is.

Second barrier that appeared in the data were some aspects of the Czech national and business culture, such as the unwillingness to share best practices and failures across companies or the general lack of competencies in the field. This precludes the whole field from learning and moving forward.

There was a person [at a conference] who was talking about how their company was great. So I didn't learn anything that I wouldn't know already. I don't know if it's typically Czech, because they show really nice case studies abroad. Although it is difficult to bring it here from the US, but nobody does it here. Everybody guards his/her limited knowledge. (financial)

Also, since marketers do not learn about other marketers' failures, it may lead to the frustration from being the only one.

\section{Conclusions}

The goal of the paper was to explore the local manifestation of the barriers to marketing's effectiveness and efficiency. Such barriers, as described in literature, include the tactical short-term orientation of marketing operations, the lack of marketing's influence on general strategy, the lack of measures to link the marketing operations and its financial effects and the image of the marketing department within the company. These barriers often coincide with the barriers to market orientation of the company, which represents one of the key elements for its profitability [3], [10].

Our data showed that the above mentioned barriers to marketing's effectiveness and efficiency do exist in the local Czech setting and are encountered on everyday basis by the interviewed marketers, but that there also seem to be barriers not found in other literature (the unwillingness to alter the perceived content of marketing and the unwillingness of marketers to share their experience).

What was found as most crucial is the narrow focus of the marketing department, which causes its short-term orientation. This is 
strengthened by the lack of use of measures that would calculate the long-term effect of marketing operations and the pressure on short-term profit from the top management. The marketers' work is then complicated by the misconception of marketing's function by its colleagues and by the CEO, who is crucial in defining the marketing's competencies, budget and strategic involvement. These barriers are then strengthened by the current economic recession, which increases pressures on accountability of all costs, and thus strengthens the short-term orientation (due to the better accountability of short-term operations).

Our data, however, also showed that there are big differences across different sectors, company sizes and ownership types. To summarize and synthesize our findings, we constructed a tentative model, in which we estimate four basic types of companies differing with respect to the role marketing plays within them. These are "B2C Marketing Oriented", "B2C Sales Oriented", "B2B Marketing Oriented" and "B2B Sales Oriented" (see fig. 1).

In case of "B2C Marketing Oriented" companies, marketing department plays rather strategic role. It ensures synergy among company's departments. Marketing department is typically large and does not seem to face problems with defending its budget. Effectiveness of the marketing function is high. The company should therefore focus primarily on efficiency of marketing activities.

Marketing in "B2C Sales Oriented" companies is still a relatively strong department. However, it is focused primarily on marketing communications. It is the sales department which controls the company. Effectiveness of the marketing function should be increased distinctly.

In "B2B Marketing Oriented" companies marketing and sales are strongly interconnected. The company acquires and retains customers by personal contacts, marketing communications plays negligible role. The company should focus primarily on efficiency of marketing activities.

In "B2B Sales Oriented" companies marketing plays insignificant role, focused primarily on sales support. It is perceived as a less important department and its budget is cut easily. In this case effectiveness of the marketing function should be increased distinctly.

What seems to play an important role in increasing marketing's reputation and securing the support of other colleagues is internal marketing.

\section{Fig. 1: Company typology with respect to the role of marketing}

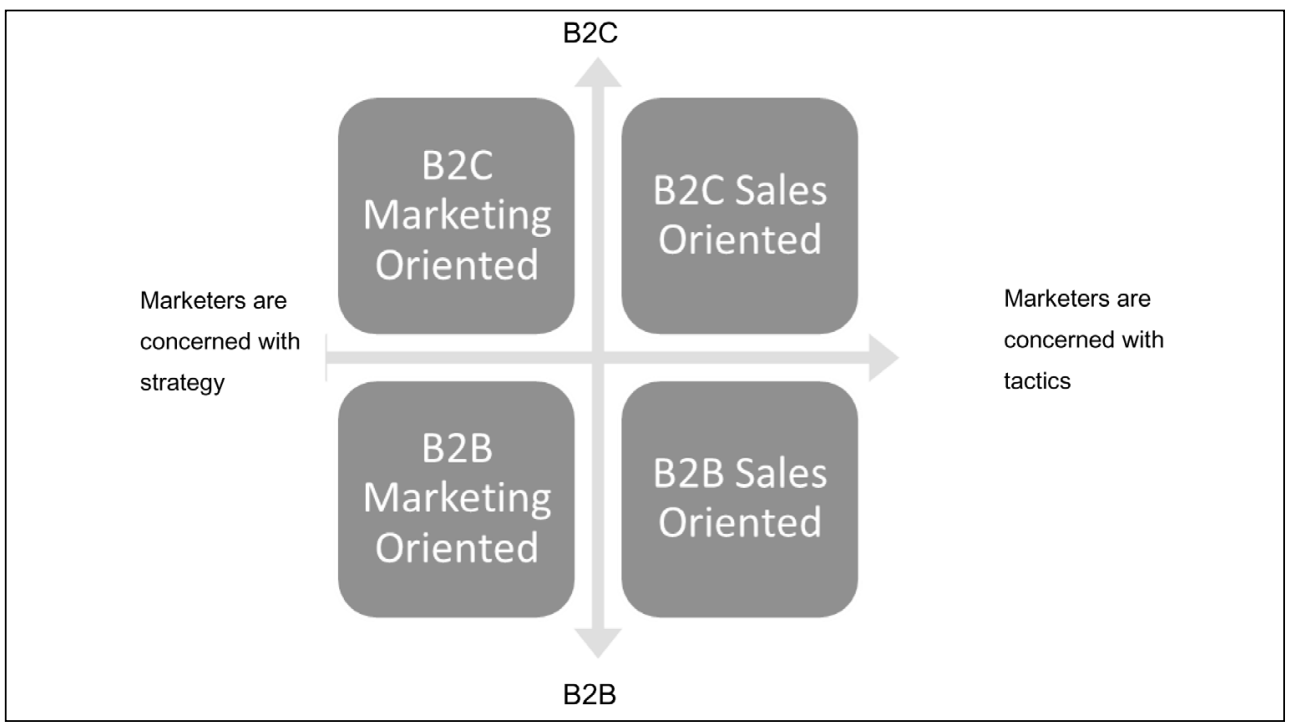


Apart from the barriers described in international marketing literature, however, our data also reveals barriers found in our specific context and not mentioned by other studies. In particular, what was found was the closeness and unwillingness to share.

\section{Managerial Recommendations}

In general, for increasing marketing effectiveness and efficiency the role of the CEO seems to be critical. The CEO should first of all appoint the position of $\mathrm{CMO}$. He or she should concentrate on hiring such a person for this position who would possess strategic, financial and analytical skills and knowledge as well as ambition to do marketing in its broadest sense. Secondly, the CEO should support strongly and continuously the CMO's efforts within the company. The CMO should not be responsible just for marketing communications but for both strategic and operational marketing decisions.

Further, the CEO, the CMO and the CFO should agree on the usage of both short-term and long-term criteria for measuring marketing ROI. Both criteria should become part of the company's overall business criteria and should become basis for the CMO's compensation. The CEO should control performance of the $\mathrm{CMO}$ according to the criteria agreed. However, he or she should respect that marketing is connected with some degree of failure. Evaluation of the CMO's performance requires therefore a certain level of understanding.

The CMO should be continuously explaining benefits of marketing activities to other departments of the company. Setting up regular formal or informal meetings, for instance, seems to be an effective strategy in this regard, as does inventing creative ways to engage colleagues from other departments in marketing's activities. At the same time he or she should continuously search for new measures of the success of marketing activities. At least in larger companies CMOs should consider investment into such IT systems which would increase measurability of marketing effectiveness and efficiency as well as the credibility of his or her department.

\section{Research Limitations and Areas for Future Research}

This study is based on qualitative data originated from focus groups with marketing professionals. As such, it is not its goal to present statistically representative conclusions, but rather offer an insight into the current situation and individuate the heterogeneous problems marketers face in their everyday work that prevent them from being effective and efficient. In this way, the resulting typology of the different companies is also tentative and should be validated by a subsequent research.

Further research should investigate the quantitative side of the barriers to marketing's effectiveness and efficiency. In particular, it should address the quantitative distribution of the individuated barriers within different types of companies. Also, further research is needed to investigate these barriers in other contexts. In particular, it should address the barriers uncovered only in our particular context to determine, if they are context-specific or could be found in other settings as well.

Moreover, CEOs and colleagues from other departments should also be involved in the further research to get a more objective view which would give the possibility to confirm the findings.

This study was realized in cooperation with Millward Brown and it was supported from the resources for long term conceptual research development of the University of Economics, Prague (IP300040).

\section{References}

[1] BAKER, W.E., SINKULA, J.M. Market Orientation and the New Product Paradox. Journal of Product Innovation Management. 2005, Vol. 22, Iss. 6, pp. 483-502. ISSN 1540-5885.

[2] IBM. CMO C-Suite Study, 2011.

[3] JAWORSKI, B.J., KOHLI, A.K. Market Orientation: Antecedents and Consequences. Journal of Marketing. 1993, Vol. 57, Iss. 3, pp. 53-70. ISSN 0022-2429.

[4] KARLÍČEK, M., CHYTKOVÁ, Z., FISCHER, J. The Role of Marketing in Corporations within the Post Communist Context: Perceptions of Marketing Managers in Czech Corporations. Studia Commercialia Bratislavensia. 2013, Vol. 6, Iss. 21, pp. 45-55. ISSN 1337-7493.

[5] KARLÍČEK, M., et al. The Role of Marketing in Multinational Subsidiaries: Standardization Versus Localization. E+M Ekonomie a Management. 2013, Vol. 16, Iss. 1, pp. 138-148. ISSN 1212-3609.

[6] KARLÍČEK, M., DRÁBIK, P. Marketing's Influence within Companies: Current Issues and 
their Possible Resolution. Studia Commercialia Bratislavensia. 2012, Vol. 5, Iss. 20, pp. 587-596. ISSN 1337-7493.

[7] KOHLI, A.K., JAWORSKI, B.J. Market Orientation: The Construct, Research Propositions, and Managerial Implications. Journal of Marketing. 1990, Vol. 54, Iss. 2, pp. 1-18. ISSN 0022-2429.

[8] KOTLER, P., RACKHAM, N., KRISHNASWAMY, S. Ending the War Between Sales and Marketing. Harvard Business Review. 2006, JulyAugust, pp. 1-12. ISSN 0017-8012.

[9] LEMON, K.N., SEIDERS, K. Making Marketing Accountable. In: SHETH, J.N., SISODIA, R.S. (Eds.). Does Marketing Need Reform? Fresh Perspectives on the Future. New York: M. E. Sharpe, Inc., 2006. pp. 201-208. ISBN 0-7656-1698-X.

[10] NARVER, J.C., SLATER, S.F. The Effect of a Market Orientation on Business Profitability. Journal of Marketing. 1990, Vol. 54, Iss. 4, pp. 20-35. ISSN 0022-2429.

[11] PERSSON, A., RYALS, L. Customer assets and customer equity: management and measurement issues. Marketing Theory. 2010, Vol. 10, Iss. 4, pp. 417-438. ISSN 1470-5931.

[12] RAJU, J.S. Revitalizing the Role of Marketing in Business Organizations: What Can Poor Academics Do to Help? Journal of Marketing. 2005, Vol. 69, Iss. 10, pp. 17-19. ISSN 0022-2429. [13] SHETH, J.N., SISODIA, R.S. Does Marketing Need Reform? Journal of Marketing. 2005, Vol. 69, Iss. 10, pp. 10-12. ISSN 0022-2429.

[14] SHETH, J.N., SISODIA, R.S. How to Reform Marketing. In: SHETH, J.N., SISODIA, R.S. (Eds.). Does Marketing Need Reform? Fresh Perspectives on the Future. New York: M. E. Sharpe, Inc., 2006. pp. 324-333. ISBN 0-7656-1698-X.

[15] SHETH, J.N., SISODIA, R.S., BARBULESCU, A. The Image of Marketing. In: SHETH, J.N., SISODIA, R.S. (Eds.). Does Marketing Need Reform? Fresh Perspectives on the Future. New York: M. E. Sharpe, Inc., 2006. pp. 26-36. ISBN 0-7656-1698-X.

[16] SLATER, S.F., NARVER, J.C. Market Orientation and the Learning Orientation. Journal of Marketing. 1995, Vol. 59, Iss. 7, pp. 63-74. ISSN 0022-2429.

[17] SMITH, J.W. Coming to Concurrence. In: SHETH, J.N., SISODIA, R.S. (Eds.). Does Marketing Need Reform? Fresh Perspectives on the Future. New York: M. E. Sharpe, Inc., 2006. pp. 15-25. ISBN 0-7656-1698-X.

[18] SPIGGLE, S. Analysis and interpretation of qualitative data in consumer research. Journal of Consumer Research. 1994, Vol. 21, Iss. 3, pp. 491-503. ISSN 0093-5301.

[19] STRINGFELLOW, A., JAP, S.D. Leveraging Marketing's Influence in Team and Group Settings. In: SHETH, J.N., SISODIA, R.S. (Eds.). Does Marketing Need Reform? Fresh Perspectives on the Future. New York: M. E. Sharpe, Inc., 2006. pp. 229-235. ISBN 0-7656-1698-X.

[20] Teradata eCircle's Marketer's Technology Guide, 2013.

[21] WEBSTER, F.E. Back to the Future: Integrating Marketing as Tactics, Strategy, and Organizational Culture. Journal of Marketing. 2005, Vol. 69, Iss. 10, pp. 4-6. ISSN 0022-2429.

[22] WEBSTER, F.E. Marketing: A Perpetual Work in Progress. In: SHETH, J.N., SISODIA, R.S. (Eds.). Does Marketing Need Reform? Fresh Perspectives on the Future. New York: M. E. Sharpe, Inc., 2006. pp. 287-294. ISBN 0-7656-1698-X.

doc. Ing. Miroslav Karlíček, Ph.D. University of Economics, Prague Faculty of Business Administration Department of Marketing miroslav.karlicek@vse.cz

Ing. Zuzana Chytková, Ph.D. University of Economics, Prague Faculty of Business Administration Department of Marketing zuzana.chytkova@vse.cz

Ing. Ladislav Tyll, Ph.D. University of Economics, Prague Faculty of Business Administration Department of Business Administration tylll@vse.cz

doc. Ing. Hana Mohelská, Ph.D. University of Hradec Králové Faculty of Informatics and Management Department of Management hana.mohelska@uhk.cz 


\title{
Abstract
}

\section{BARRIERS OF MARKETING EFFECTIVENESS AND EFFICIENCY WITHIN COMPANIES: A QUALITATIVE STUDY}

\author{
Miroslav Karlíček, Zuzana Chytková, Ladislav Tyll, Hana Mohelská
}

Market orientation can be defined as the company's ability to systematically generate relevant information about current and latent customer needs, spread this information across all company departments and use this information in decision making and subsequent behavior. Current research proves that market orientation correlates strongly with profitability. Strengthening market orientation should therefore be the main focus of the marketing department. However, over the last years, marketers within companies have faced serious criticism coming from the top management as well as from other business functions. This criticism stems from the generally shared opinion that marketing expenditures tend to rise whereas marketing effectiveness and efficiency seem to decline over time, as proved by relatively low satisfaction and loyalty levels of customers and their resistance towards marketing activities. This study investigates the main barriers of marketing effectiveness and efficiency within companies. Based on two focus groups with senior Czech marketing managers we revealed several key themes that reflect how local marketers perceive their jobs. We identified that marketing departments differ diametrically in activities they execute, that marketers face image problem within their companies and that they are not able to prove return of their activities sufficiently. Furthermore, we individuated barriers specific for our context not found in the literature. However, companies of different size and sectors have specifics which are discussed in the text. Managerial recommendations are added. All of these findings should be of high importance for both CEOs (resp. owners) and marketers, because increasing effectiveness and efficiency of the marketing function is their common goal.

Key Words: Marketing function, marketing effectiveness, marketing efficiency, marketing department, marketing manager.

JEL Classification: M31.

DOI: 10.15240/tul/001/2014-4-009 